\title{
Follicular Cholecystitis Mimicking Xanthogranulomatous Cholecystitis and Malignancy: A Case Report
}

\author{
Martina Aineseder $^{1}$ Roy López Grove ${ }^{1} \quad$ Eduardo G. Mullenl ${ }^{2} \quad$ Juan C. Spina ${ }^{1}$ \\ ${ }^{1}$ Departments of Radiology, Hospital Italiano de Buenos Aires, Peron, \\ Buenos Aires, Argentina \\ 2 Departments of Pathology, Hospital Italiano de Buenos Aires, Peron, \\ Buenos Aires, Argentina \\ Address for correspondence Martina Aineseder, Department of \\ Radiology, Hospital Italiano de Buenos Aires, Peron 4190, Buenos \\ Aires, Argentina (e-mail: martina@aineseder.com). \\ Indian J Radiol Imaging 2021;31:697-700.
}

\begin{abstract}
Keywords

- follicular cholecystitis

- magnetic resonance imaging

- xanthogranulomatous cholecystitis

Chronic follicular cholecystitis (CFC) is a rare pathology characterized by prominent lymphoid follicles in the lamina propria distributed throughout the gallbladder wall. It has also been mentioned in the literature as lymphoid hyperplasia and pseudolymphoma. CFC represents less than $2 \%$ of cholecystectomies. Its etiopathology is mostly unknown. Most reports are based on histopathological findings, with little or no imaging analysis. We describe a case involving a 66-year-old man radiologically diagnosed as xanthogranulomatous cholecystitis (XGC) versus malignancy, revealing CFC with surrounding inflammatory changes in the cholecystectomy specimen.
\end{abstract}

\section{Introduction}

Chronic follicular cholecystitis (CFC) is a rare entity that represents less than $2 \%$ of cholecystectomies. All reported cases have been managed surgically with the diagnosis made postoperatively based on histological findings. ${ }^{1}$ To the best of our knowledge, there are no magnetic resonance imaging (MRI) reports about this pathology. We present a case of CFC and describe and illustrate the imaging findings. For the first time, we report the presence of surrounding inflammatory changes.

\section{Case Presentation}

A 66-year-old man was referred to our hospital for having right-sided abdominal pain and dyspepsia. The patient's symptoms had started 4 months ago. The patient's medical history was unremarkable except for the presence of high blood pressure. The physical abdominal examination was unremarkable. The laboratory findings showed elevated erythrocyte sedimentation rates $(45 \mathrm{~mm})$, normal leuko- cytes count $(8900 / \mathrm{mL})$ with $65 \%$ of segmented neutrophils, an elevated carbohydrate antigen 19-9 (CA 19-9) of 531.9 $\mathrm{UI} / \mathrm{L}$, and normal carcinoembryonic antigen (CEA) of 1.8 $\mathrm{UI} / \mathrm{L}$.

Abdominal ultrasound (US) was performed, which showed a heterogeneous thickening of the gallbladder fundus wall with low resistance flow on power Doppler and hypoechoic intramural nodules ( $\mathbf{- F i g . ~ 1 ) . ~ T h e ~ M R I ~ r e v e a l e d ~}$ intramural nodules with elevated T2WI signal intensity (-Fig. 2) and heterogeneous signal intensity and contrastenhancement of the thicken fundus wall ( - Fig. 3). Diffusionweighted imaging (DWI) showed an increase in signal intensity on successively higher-b-value DWI images and low signal intensity on the corresponding apparent diffusion coefficient (ADC) map, with a value of $0.9 \times 10^{-3} \mathrm{~mm}^{2} / \mathrm{s}$ (-Fig. 4). The surrounding gallbladder and liver parenchyma had inflammatory changes.

A presumptive diagnosis of xanthogranulomatous cholecystitis (XGC) versus gallbladder carcinoma was made and surgery was performed. No preoperative fine-needle aspiration or biopsy was made because suspicion of gallbladder
DOI https://doi.org/ 10.1055/s-0041-1736163. ISSN 0971-3026.

\footnotetext{
(C) 2021. Indian Radiological Association. All rights reserved. This is an open access article published by Thieme under the terms of the Creative Commons Attribution-NonDerivative-NonCommercial-License, permitting copying and reproduction so long as the original work is given appropriate credit. Contents may not be used for commercial purposes, or adapted, remixed, transformed or built upon. (https://creativecommons.org/ licenses/by-nc-nd/4.0/)

Thieme Medical and Scientific Publishers Pvt. Ltd., A-12, 2nd Floor, Sector 2, Noida-201301 UP, India
} 


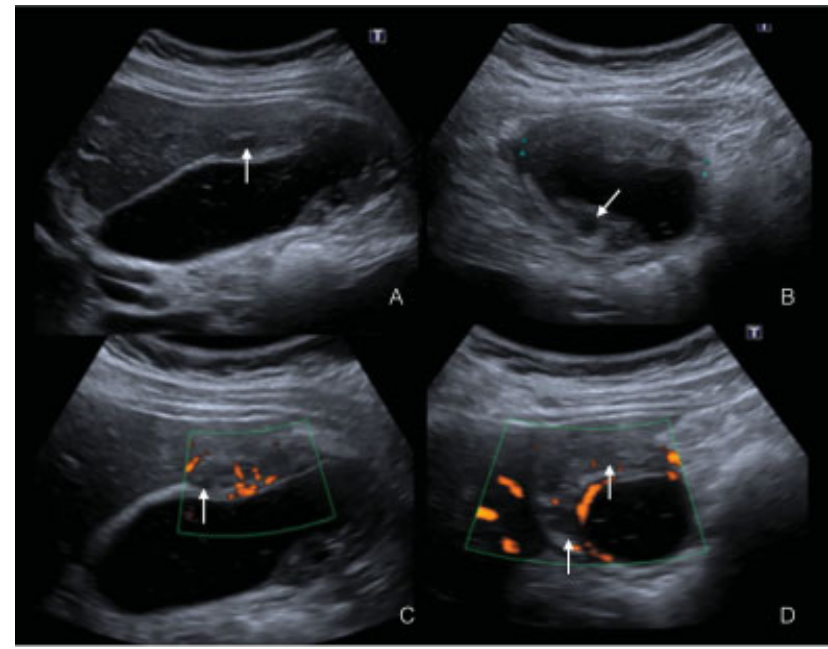

Fig. 1 (A-D) Ultrasound. A heterogeneous thickened gallbladder wall is shown with low resistance flow on power Doppler and hypoechoic intramural nodules (arrows).

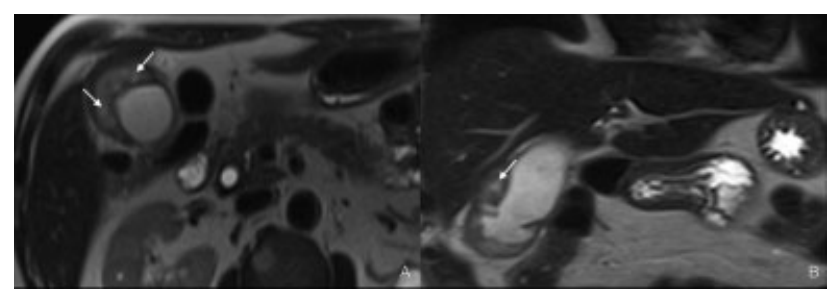

Fig. 2 (A and B) MRI. Axial (A) and coronal (B) T2WI show a heterogeneous thickened gallbladder fundus wall with high-intensity nodules, similar to XGC. XGC, xanthogranulomatous cholecystitis.

cancer was high due to the size of the lesion and the high values of CA 19-9. The gallbladder was found adhered to the adjacent omentum, transverse colon, and liver parenchyma

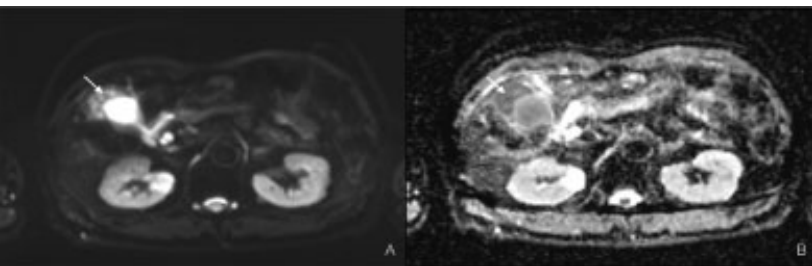

Fig. 4 (A and B) MRI. DWI (A) and ADC (B) show restriction in the thickened wall (arrow). ADC, apparent diffusion coefficient; DWI, diffusion-weighted imaging; MRI, magnetic resonance imaging.

cholecystectomy, atypical hepatic segmentectomy of segments IVb, and $\mathrm{V}$, and segmentary resection of the transverse colon were done due to adhesions between the gallbladder and surrounding organs (-Fig. 5). The specimen was sent to the department of pathology for histopathological examination.

The hematoxylin and eosin (H\&E)-stained section from the gallbladder showed proliferating or reactive lymphoid follicles with prominent germinal centers along with chronic inflammatory infiltrate comprising lymphocytes, histiocytes, eosinophils, and plasma cells underlying the lamina propria throughout the thickness of the gallbladder wall. There was no necrosis, atypical cells, and xanthomized histiocytes. This tissue infiltrated the liver parenchyma and adjacent colonic wall. Extensive areas of fibrosis were recognized, forming dense septa that dissected and intermingled with the infiltrate areas. Liver parenchyma showed portal spaces with chronic mononuclear inflammatory infiltrate and stromal fibrosis (-Fig. 6). Pathological diagnosis of CFC of the gallbladder with the liver and colon involvement was made.

The postoperative course was uneventful and the patient was discharged 10 days after surgery.

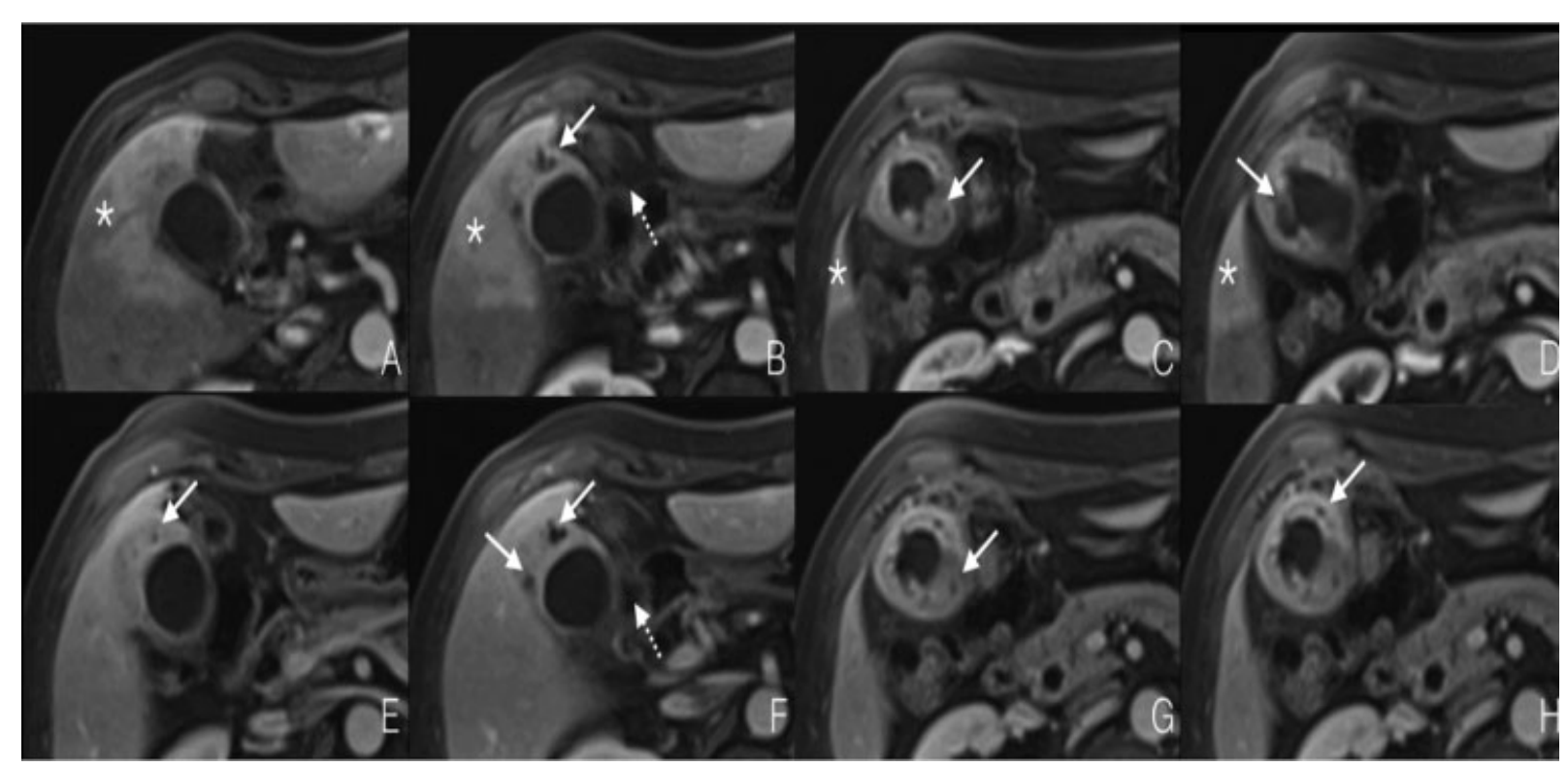

Fig. 3 (A-H) MRI. Contrast-enhanced arterial (A-D) and portal phases (E-H) show a heterogeneous contrast-enhancement of the thickened fundus wall. The intramural nodules remain hypointense (arrows). The surrounding liver parenchyma (asterisk) and mesenteric fat adjacent to the gallbladder (dotted arrow) show inflammatory changes. MRI, magnetic resonance imaging 


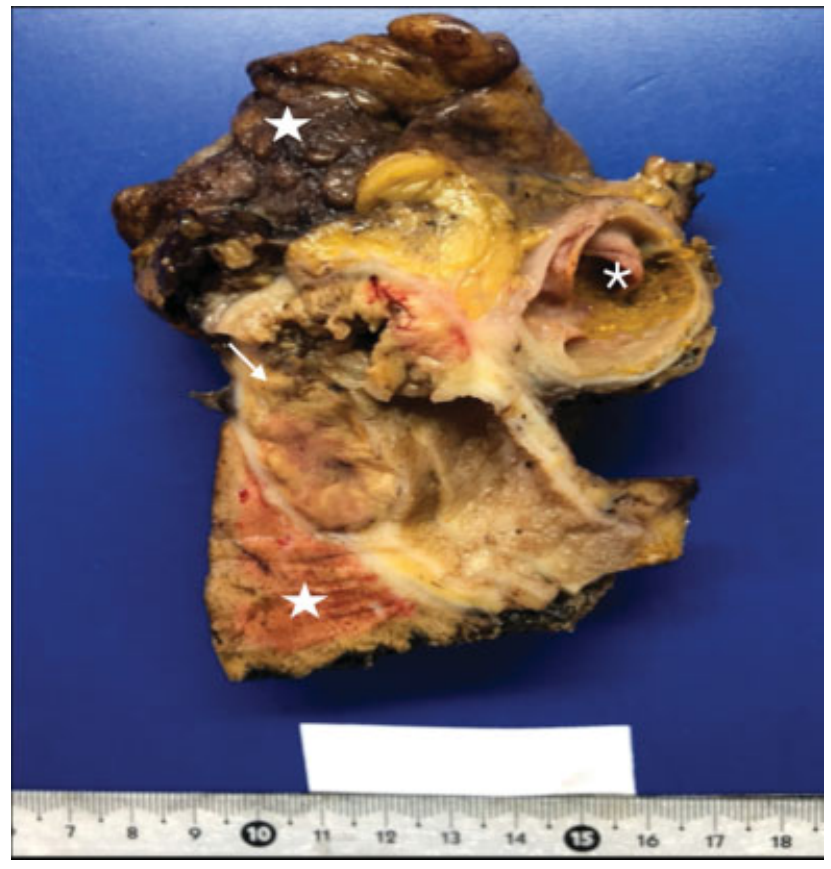

Fig. 5 Gross pathology. Surgical piece that included cholecystectomy, atypical hepatic segmentectomy of segments IVb and V, and segmentary resection of the transverse colon. Thickened gallbladder wall (arrow), liver (star), and colon (asterisk).

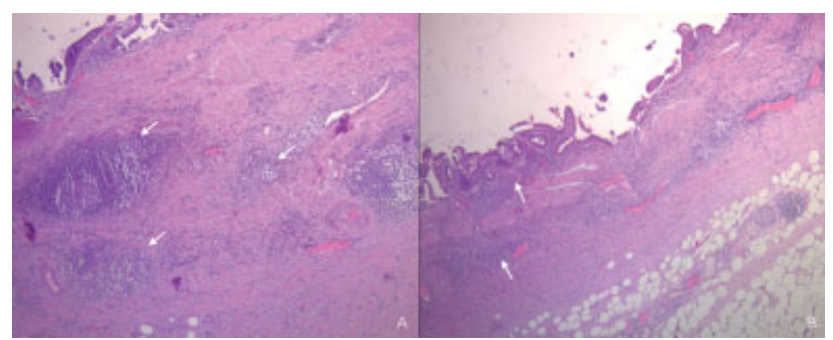

Fig. 6 Histopathology. H\&E 100x show gallbladder wall with intraparietal lymphoid accumulations (arrows). H\&E, hematoxylin and eosin.

\section{Discussion}

CFC is a very rare benign entity with only a few cases published in the literature. ${ }^{2,3}$ It represents less than $2 \%$ of cholecystectomies. ${ }^{1,4}$ CFC has been mentioned as lymphoid hyperplasia, pseudolymphoma, and chronic cholecystitis with lymphoid hyperplasia. It was first described on cholecystograms by Estrada et $\mathrm{al}^{5}$ in 1960 . Being a highly uncommon pathology, the literature reports different opinions about this entity. ${ }^{6}$ It is characterized by hyperplastic lymphoid follicles with germinal centers consisting of polymorphous lymphoid populations. ${ }^{7,8}$ For the diagnosis, an increase in the number of intraepithelial lymphocytes per 100 biliary cells above the normal proportion of three to four lymphocytes is needed. ${ }^{9}$

The pathogenesis of CFC is unclear although it may be caused by an immune reaction to luminal agents of the gallbladder. ${ }^{10}$ Other theories include an autoimmune-mediated disorder in other areas of the gastrointestinal tract or gram-negative bacterial infection that induce a lymphocytic reaction, such as E. coli, K. pneumoniae, or $S$. typhi. ${ }^{9-11}$ This inflammatory pattern can be encountered in other parts of the gastrointestinal tract such as the esophagus, stomach, duodenum and colon, and in the orbits and lungs. ${ }^{8}$

Risk factors for developing CFC are unclear because there are uncertain causal associations. It seems to affect more frequently middle-aged or elderly females, and other conditions such as chronic hepatitis, thyroiditis, or primary biliary cirrhosis can coexist. ${ }^{8}$ Differential diagnoses arise mainly between XGC and gallbladder carcinoma. XGC is an unusual variant of chronic cholecystitis that is characterized by a lipid-laden inflammatory process that can invade neighboring structures and can be blended with cancer. Moreover, it is a challenging diagnosis as there are imaging similarities between XGC and gallbladder cancer such as the enhancing and thickened wall, and the tendency to involve neighboring organs.

Findings such as intramural hypoattenuated nodules occupying $60 \%$ of the area of the thickened wall, intact enhancing mucosal lining, absence of biliary tract dilatation, no large masses, and absence of lymph nodes suggest a diagnosis of XGC instead of cancer. ${ }^{12}$

In our case, the gallbladder had diffuse parietal thickening, intramural nodules with elevated T2WI signal intensity, and preservation of linear mucosal enhancement, similar to an XGC. However, the intramural nodules did not show signal fall on opposed-phase images as in XGC. It must be taken into account that although they share epidemiological characteristics regarding age and sex, XGC does not present a clear association with gallbladder cancer, ${ }^{13}$ even though metaplastic changes can be found in up to $75 \%$ of patients with CFC. However, its relationship with gallbladder carcinogenesis is unclear too. ${ }^{1}$ In our case, no metaplastic changes were found.

We found no report regarding the adhesions and fibrosis to the liver and colon in CFC. As CFC is thought to be caused by an immune reaction, chronic gallbladder inflammation may induce a progressively irreversible fibrotic response that can affect surrounding tissues. The surrounding fatty tissue had a high signal intensity on the T2-weighted and fat-suppressed images, and the liver parenchyma adjacent to the gallbladder showed enhancement at the arterial phase, both representing the inflammatory changes. We had no previous imaging examinations to determine when these changes started.

Sometimes, the difficulty to distinguish XGC from gallbladder carcinoma derives from extensive surgical resections. It is important to consider CFC as a differential diagnosis, and in some cases perform a frozen section of the gallbladder to arrive at a correct diagnosis and avoid wider surgical resections.

Funding

None.

Conflicts of Interest

There are no conflicts of interest. 
700 Follicular Cholecystitis Mimicking Xanthogranulomatous Cholecystitis and Malignancy Aineseder et al.

\section{References}

1 Kocaöz S, Turan G. Preneoplastic and neoplastic gallbladder lesions detected after cholecystectomy. Prz Gastroenterol 2019;14(03): 193-197

2 Gu L, Comeau E, Geha S. Même une cholécystite peut vous surprendre. Ann Pathol 2017;37(04):333-337

3 Singh M, Vishwakarma I, Kumar J, Omhare A, Mishra V, Verma YN. Follicular cholecystitis with cholelithiasis: a rare case. Int J Life Sci Scienti Res 2017;3:1408-1410

4 Salari B, Rezaee N, Toland A, Chatterjee D. Follicular cholecystitis: clinicopathologic associations. Hum Pathol 2019; 88:1-6

5 Estrada RL, Brown NM, James CE. Chronic follicular cholecystitis. Radiological, pathological and surgical aspects. Br J Surg 1960; 48:205-209

6 Rosai J. Rosai and Ackerman's Surgical Pathology. 9th ed. St. Louis: Elsevier Mosby; 2004
7 Hussain SA, English WE, Lytle LH, Thomas DW Jr. Pseudolymphoma of the gallbladder. Am J Gastroenterol 1976;65(02):152-155

8 Rana S, Jairajpuri ZS, Khan S, Hassan MJ, Jetley S. Gall bladder lymphoid hyperplasia: masquerading as lymphoma. J Cancer Res Ther 2014;10(03):749-751

9 Vats AD, Gupta V, Mehendiratta M, Anand N. Chronic cholecystitis with follicular lymphoid hyperplasia: nomenclature and diagnostic dilemmas. Int J Res Med Sci 2019;7:770-775

10 Vanderhoof JA, Young RJ. Allergic disorders of the gastrointestinal tract. Curr Opin Clin Nutr Metab Care 2001;4(06):553-556

11 Sternberg SS, Mills SE, Carter D. Sternberg's Diagnostic Surgical Pathology. Philadelphia: Lippincott Williams \& Wilkins; 2004

12 Jain S, Saluja SS, Sharma AK, Sant H, Mishra PK. Xanthogranulomatous cholecystitis: catching the culprit-clinical and imaging analysis. Dig Surg 2012;29(03):187-193

13 Dixit VK, Prakash A, Gupta A, et al. Xanthogranulomatous cholecystitis. Dig Dis Sci 1998;43(05):940-942 